\title{
Microstructure of As-cast Ferritic-pearlitic Nodular Cast Irons
}

\author{
Jacques LACAZE, ${ }^{1) *}$ Jon SERTUCHA ${ }^{2)}$ and Lena MAGNUSSON ÅBERG ${ }^{3)}$ \\ 1) CIRIMAT, Université de Toulouse, 31030, Toulouse, France. $\quad$ 2) Engineering and Foundry Process Department, IK4- \\ Azterlan, 48200, Durango (Bizkaia), Spain. $\quad 3)$ Elkem AS Foundry Products R\&D, P.O. Box 8040 Vaagsbygd, NO-4675,
} Kristiansand, Norway.

(Received on March 2, 2016; accepted on May 18, 2016)

\begin{abstract}
A review of past works on the formation of ferrite and pearlite in nodular cast iron is proposed. The effects of cooling rate after solidification and of nodule count on the formation of both constituents are stressed, though much emphasis is put on alloying elements and impurities.
\end{abstract}

KEY WORDS: nodular cast iron; as-cast microstructure; ferrite; pearlite; alloying

\section{Introduction}

Nodular cast irons are composite materials made of graphite spheroids embedded in a Fe-rich matrix. Their mechanical properties depend both on nodule count and on the matrix constitution resulting from the transformation of high-temperature austenite formed together with graphite during the solidification step. In as-cast materials, this transformation can lead to ferrite or pearlite, or to a mix of them, and sometimes to martensite in case of highly alloyed irons cast in small sections. Bainite is not observed in as-cast irons, it is obtained after appropriate heat-treatment and will not be considered further here where focus is put on as-cast irons with ferritic-pearlitic structures. The ferritic-pearlitic matrix consists of halos of ferrite around the nodules and pearlite away from them (last to freeze areas), giving the so-called bulls-eye structure illustrated in Fig. 1.

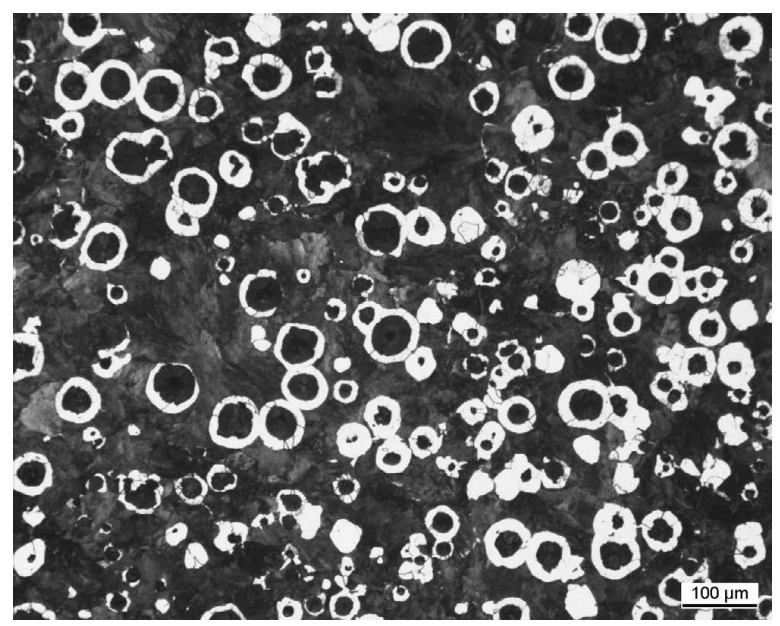

Fig. 1. Bull-eyes structure of nodular cast irons showing halos of ferrite (white contrast) around graphite nodules (dark contrast), the remaining of the matrix being pearlite (dark grey contrast).

\footnotetext{
* Corresponding author: E-mail: jacques.lacaze@ensiacet.fr DOI: http://dx.doi.org/10.2355/isijinternational.ISIJINT-2016-108
}

One of the most relevant advantages of nodular cast iron is their extensive application in the as-cast condition. This reduces the manufacturing cost and potential problems related to variability from heat-treatment are avoided. The first section below deals with the principle of the eutectoid transformation of austenite in the stable and metastable systems, putting emphasis on the role of alloying elements (mostly pearlite promoting elements). The following section is devoted to attempts to predict room temperature matrix structure on the basis of melt composition, i.e. considering competition of ferrite and pearlite. In the conclusion, some proposals for further studies in this field will be detailed.

\section{Eutectoid Transformation of Austenite}

Among a few other authors, Johnson and Kovacs ${ }^{1)}$ have described how the microstructure in Fig. 1 evolves, with austenite starting to decompose in the stable system giving ferrite halos growing symmetrically around graphite nodules. Further growth of ferrite involves transfer of carbon from the remaining austenite to graphite nodules by diffusion through the ferrite halo (this will hereafter be called the ferritic reaction). The process is thus slower and slower as the thickness of the halos increases. Hence, upon continuous cooling of the material, the temperature can become low enough for nucleation and growth of pearlite in the metastable system (hereafter called the pearlitic reaction). Pearlite growth is comparatively rapid because it proceeds by cooperative (coupled) growth of cementite and ferrite, certainly much like in steels according to Pan et al. ${ }^{2)}$ and Venugopalan. ${ }^{3)}$ Further, Johnson and Kovacs ${ }^{1)}$ could show that pearlite appears at the ferrite/austenite interface and develops as spherical colonies inside the remaining austenite. Thus, ferrite can still grow after the pearlitic reaction has started, but the growth rate of this latter is such that austenite decomposition is most generally quickly completed.

An important number of foundries include thermal analysis for controlling melt preparation before casting using commercial standard rig and cups. Figure 2 shows an example of such a record when the output has been 


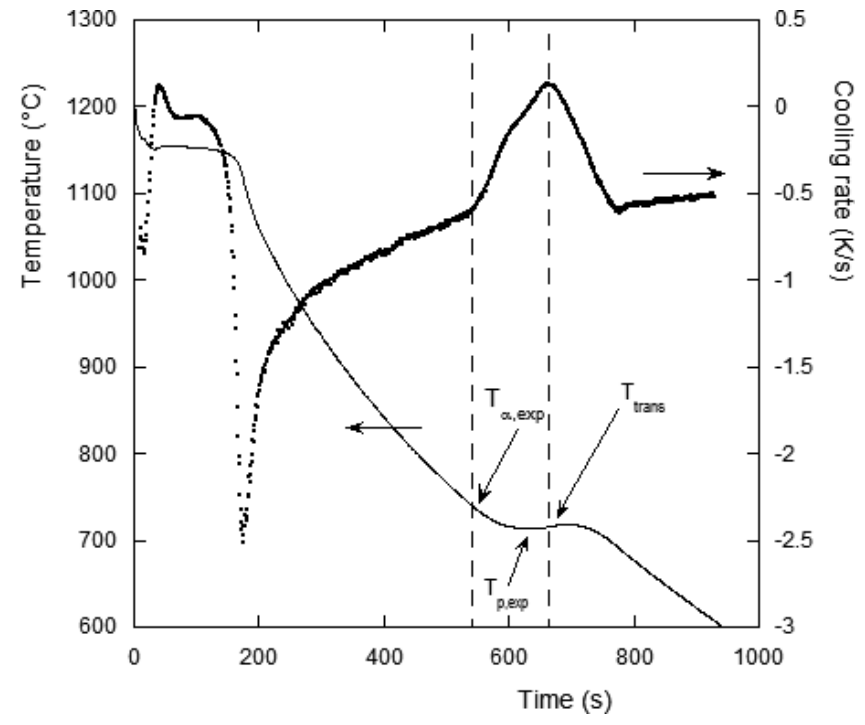

Fig. 2. Cooling curve and its derivative obtained by casting a standard thermal analysis cup with a nodular cast iron (3.74 C, 2.51 Si, 0.18 Mn, 0.68 Cu, wt.\%) after Sertucha et al. ${ }^{4)} \mathrm{T}_{\alpha, \exp }, \mathrm{T}_{\mathrm{p}, \exp }$ and $\mathrm{T}_{\text {trans }}$ are respectively the experimental temperatures for the start of the ferritic and pearlitic reactions, and for the maximum in the derivative curve.

pursued down to low enough temperature to register the solid-state transformation of the alloy. The derivative of the temperature with respect to time (i.e. the cooling rate) is also plotted which shows that both solidification and solid-state transformations appearing as plateaus on the cooling curve give sharp changes in the derivative. Focusing on the part of the derivative record corresponding to the solid-state transformation, it is seen that it could be divided in two bellshape signals, which correspond to the ferritic and pearlitic reactions. On such curves it is possible to measure the cooling rate of the material before the eutectoid transformation and the temperatures for the start of the ferritic and pearlitic reactions. Integration of the area below the derivative peak could also lead to a first estimate of the transformation kinetics. The same characterization could be performed as well on differential thermal analysis (DTA) records where the cooling rate is imposed.

\subsection{Formation of Ferrite}

Figure 3 schematically illustrates ferrite growth described above. One particular feature of the ferritic reaction is the fact that no redistribution of substitutional elements at the ferrite/austenite interface has been reported for as cast materials. In other words, the ferrite inherits the alloying content of the parent austenite, this is the so-called para-ferrite mentioned by Venugopalan, ${ }^{3)}$ see appendix. If one assumes the matrix is chemically homogeneous, an isopleth $\mathrm{Fe}-\mathrm{C}$ section of the relevant system, e.g. the one drawn at $2.5 \mathrm{wt} . \%$ silicon in Fig. 4, is thus relevant for describing austenite/ graphite equilibrium at temperatures above the three-phase domain, and ferrite/graphite equilibrium at temperatures below this domain. It is worth noting the very low level of carbon that can dissolve in ferrite as compared to that in the parent austenite. During growth of ferrite, carbon can be rejected partly to austenite but growth of graphite will proceed mainly by diffusion of carbon to graphite through the ferrite halo. Following Lacaze et al., ${ }^{5-7)}$ the schematic of

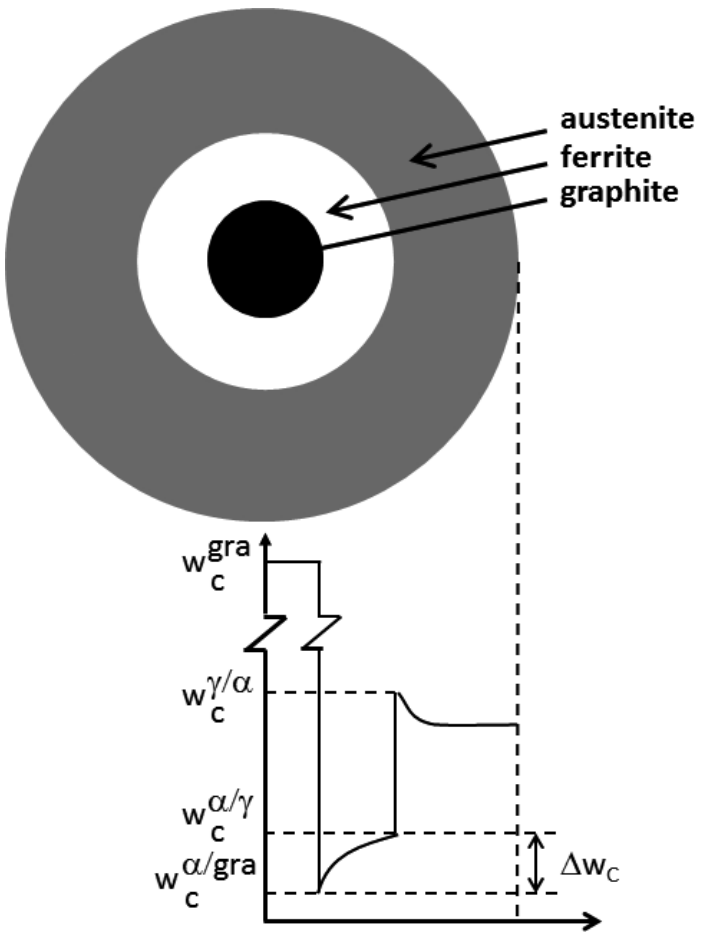

Fig. 3. Schematic of ferrite formation as halos around the graphite nodules and corresponding radial carbon distribution. $\Delta \mathrm{w}_{\mathrm{C}}$ should be positive for carbon to diffuse to graphite from the ferrite/austenite interface to the graphite nodule.

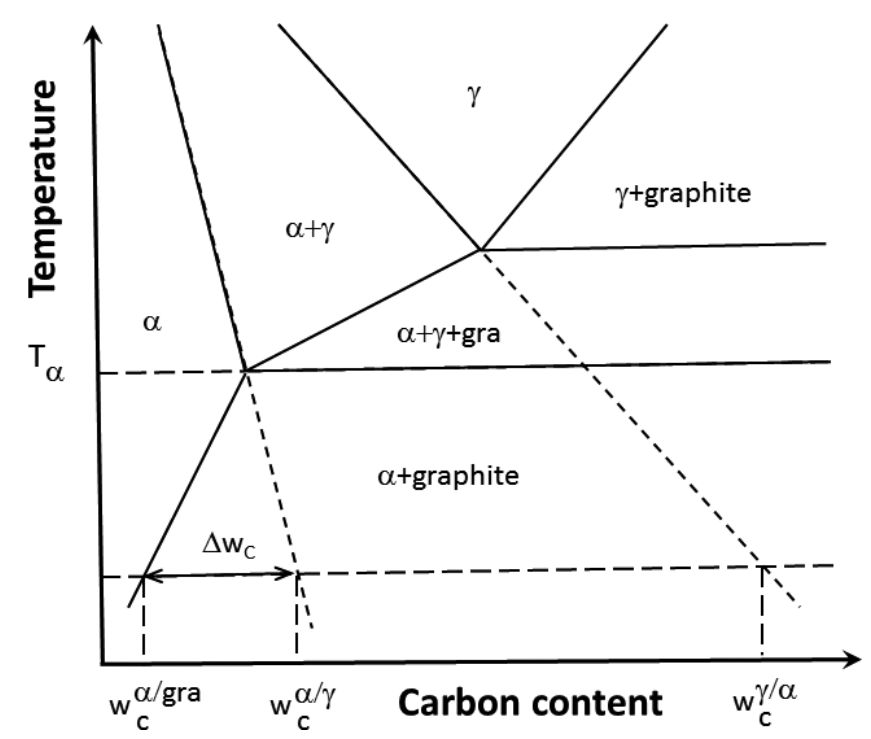

Fig. 4. Isopleth $\mathrm{Fe}-\mathrm{C}$ section of the $\mathrm{Fe}-\mathrm{C}-\mathrm{Si}$ system at $2.5 \mathrm{wt} . \%$ $\mathrm{Si}$ in the stable eutectoid range. $\Delta \mathrm{w}_{\mathrm{C}}$ shows the difference between the carbon content at the ferrite/austenite interface, $\mathrm{w}_{\mathrm{C}}^{\alpha / \gamma}$, and at the graphite/ferrite interface, $\mathrm{w}_{\mathrm{C}}^{\alpha / g r a}$.

carbon distribution in Fig. 3 demonstrates that this diffusion could proceed only if $\Delta \mathrm{w}_{\mathrm{C}}=\mathrm{w}_{\mathrm{C}}^{\alpha / \gamma}-\mathrm{w}_{\mathrm{C}}^{\alpha / \mathrm{gra}}$ is positive, where $\mathrm{w}_{\mathrm{C}}^{\alpha / \gamma}$ and $\mathrm{w}_{\mathrm{C}}^{\alpha / \text { gra }}$ are the carbon content in ferrite $(\alpha)$ in equilibrium with austenite $(\gamma)$ and graphite (gra) respectively. This condition is fulfilled at temperatures below the three phase field (see Fig. 4), meaning that the carbon content in the growing ferrite and in the receding austenite should be described by the metastable extrapolations (shown with dashed lines) of the equilibrium lines (solid lines). Note that as the temperature decreases, the carbon content in ferrite 
in equilibrium with austenite, $\mathrm{w}_{\mathrm{C}}^{\alpha / \gamma}$, and that of austenite in equilibrium with ferrite, $\mathrm{w}_{\mathrm{C}}^{\gamma / \alpha}$, increase.

Once the temperature of the alloy has reached the three phase field upon continuous cooling, ferrite could possibly nucleate but does not grow because this would involve long range redistribution of substitutional elements between ferrite and austenite. Such a redistribution needs diffusion which is very sluggish for substitutional elements at the relevant temperatures, see appendix. The ferritic reaction can thus proceed only when the temperature of the alloy has reached the temperature $\mathrm{T}_{\alpha}$ given by the intersection of the extrapolation of the austenite/ferrite boundary with the lowest limit of the three phase field. The effect of alloying on this temperature has been estimated ${ }^{8)}$ by means of thermodynamic calculations using Thermocalc ${ }^{9}$ and data from Uhrenius: ${ }^{10)}$

$$
\begin{aligned}
\mathrm{T}_{\alpha} & =739+18.4 \cdot \mathrm{w}_{\mathrm{Si}}+2 \cdot\left(\mathrm{w}_{\mathrm{Si}}\right)^{2}-14 \cdot \mathrm{w}_{\mathrm{Cu}} \\
& -45 \cdot \mathrm{w}_{\mathrm{Mn}}+2 \cdot \mathrm{w}_{\mathrm{Mo}}-24 \cdot \mathrm{w}_{\mathrm{Cr}}-27.5 \cdot \mathrm{w}_{\mathrm{Ni}}
\end{aligned}
$$

where $\mathrm{w}_{\mathrm{i}}$ is the " $\mathrm{i}$ " element content in wt.\% and $\mathrm{T}_{\alpha}$ is in Celsius. This expression has been calculated with silicon content up to 3 wt.\%, manganese, chromium, copper and nickel contents up to $1 \mathrm{wt} . \%$ and molybdenum content up to $0.5 \mathrm{wt} . \%$. The sign of their effect agrees with the role of silicon and molybdenum as ferrite stabilizers, while copper, manganese and nickel are austenite stabilizers. Contrary to what is expected, chromium presents a negative effect on $\mathrm{T}_{\alpha}$ while it is a ferrite stabilizer according to the $\mathrm{Fe}-\mathrm{Cr}$ phase diagram. This may be related to the downward shape of the gamma loop in the $\mathrm{Fe}-\mathrm{Cr}$ system.

Note that the average composition of austenite $\mathrm{w}_{\mathrm{i}}^{\gamma}$ in elements other than carbon differs from the nominal composition $\mathrm{w}_{\mathrm{i}}^{\mathrm{o}}$ of the cast iron because of graphite precipitation during solidification. Evaluation of $\mathrm{T}_{\alpha}$ should thus be done for corrected compositions using the simple following mass balance:

$$
\mathrm{w}_{\mathrm{i}}^{\gamma}=\frac{\rho^{\text {gra }} \cdot \mathrm{g}^{\text {gra }}+\rho^{\gamma} \cdot\left(1-\mathrm{g}^{\text {gra }}\right)}{\rho^{\gamma} \cdot\left(1-\mathrm{g}^{\text {gra }}\right)} \cdot \mathrm{w}_{\mathrm{i}}^{\mathrm{o}}
$$

where $\rho^{\text {gra }}$ and $\rho^{\gamma}$ are the densities of graphite and austenite respectively. Putting the appropriate values in Eq. (2) leads to $\mathrm{w}_{\mathrm{i}}^{\gamma} \approx 1.05 \cdot \mathrm{w}_{\mathrm{i}}^{\mathrm{o}}$. Note also that using an average composition means not accounting for microsegregation built up during solidification which will be discussed later.

Since the early work by Rehder, ${ }^{11)}$ growth of ferrite during the eutectoid reaction is known to be highly sensitive to cooling rate. Rehder ${ }^{11)}$ showed that at very low cooling rate, precipitation of ferrite is not only related to nodules but occurs at austenite grain boundaries and proceeds with longrange redistribution of substitutional solutes between ferrite and austenite. The same observation has been reported by Brown and Hawkes ${ }^{12)}$ in case of isothermal holding in the three-phase field. Gerval and Lacaze ${ }^{8)}$ performed an analysis of data from literature which showed the above model without long range redistribution (Figs 3 and 4) applies when the cooling rate is higher than about $0.02^{\circ} \mathrm{C} \cdot \mathrm{s}^{-1}$ or $1.2^{\circ} \mathrm{C} \cdot \mathrm{min}^{-1}$. At cooling rates lower than this critical value, ferrite will form at austenite grain boundaries and its growth will be controlled by long range diffusion of substitutional solutes.
For analysis of data obtained on alloys cooled at finite rate for which the model in Fig. 3 applies, it is convenient to plot the undercooling for the start of the ferritic reaction $\left(\Delta \mathrm{T}_{\alpha}\right)$ as measured with respect to $\mathrm{T}_{\alpha}$, i.e. $\Delta \mathrm{T}_{\alpha}=\mathrm{T}_{\alpha}-\mathrm{T}$ where $\mathrm{T}$ is the temperature at which the ferritic reaction is seen to start experimentally. This is illustrated in Fig. 5 for a series of alloys containing various amounts of copper studied by Sertucha et l. $^{4)}$ It is seen that the undercooling for the start of the ferritic reaction appears to follow a power law of the cooling rate that would extrapolate to zero at zero cooling rate, thus giving an indirect support to the model.

The undercooling for the start of the reaction shown in Fig. 5 corresponds to the so-called incubation time in the literature on time temperature transformations (TTT) and continuous cooling transformations (CCT). To get further insight in the very start of the ferritic reaction, Hellal et al. ${ }^{13)}$ performed dilatometry experiments where samples were held in the austenite field and then rapidly cooled to and held at a temperature below $\mathrm{T}_{\alpha}$. During this second holding, the recorded curves showed first a contraction and then a dilation. The contraction relates to carbon depletion of austenite because its solubility in austenite strongly decreases with temperature so that the associated change in the density of austenite overtakes graphite precipitation. After some time, ferrite growth leads to the observed dilation. Hazotte et al. ${ }^{14)}$ observed however that ferrite appears very early during the second holding and that the apparent start of the ferritic reaction, i.e. when dilation sets up, relates in fact to a ferrite fraction of more than $10 \%$.

In these dilatometry experiments, the maximum in the contraction was found to be strongly related to nodule count, i.e. the diffusion distance for carbon from austenite to graphite. This suggests that, when increasing the cooling rate in a casting, the average carbon content in austenite shifts more and more to the right of the equilibrium austenite/graphite phase boundary (graphite solvus) because there is less and less time for austenite depletion. This is illustrated schemati-

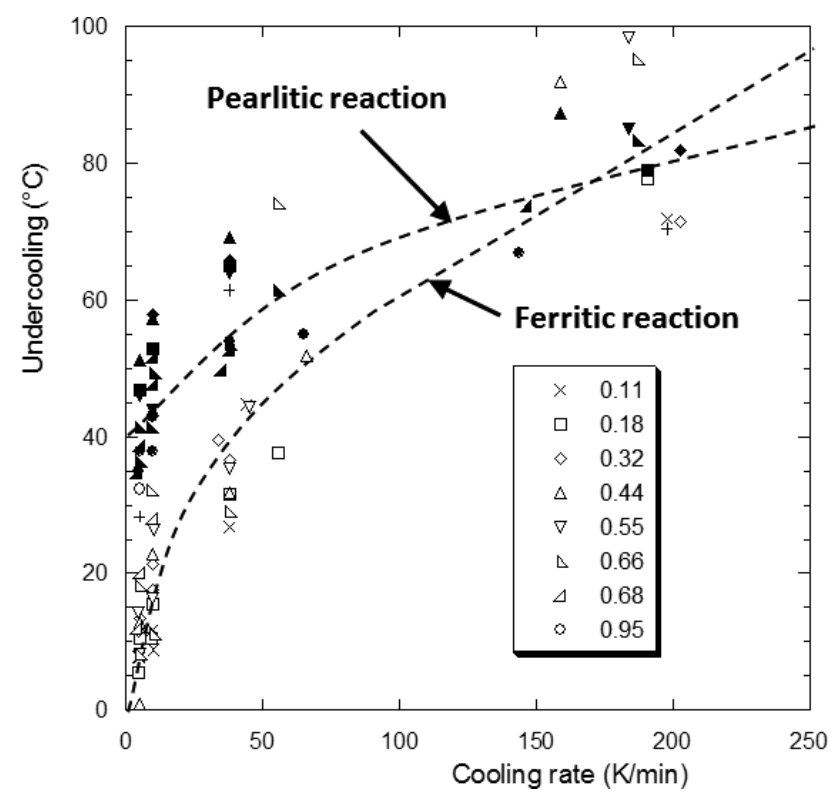

Fig. 5. Evolution with cooling rate of the start of the ferritic and pearlitic reactions measured on alloys with 3.6-3.8 C, 2.47-2.83 Si, 0.12-0.19 $\mathrm{Mn}$ and 0.11-0.95 $\mathrm{Cu}$ (indicated in the caption), in wt.\%, after Sertucha et al. ${ }^{4)}$ 
cally in Fig. 6 where it is suggested that high cooling rates could lead to conditions where ferrite becomes stable only at temperatures far below the stable three phase field, i.e. at the intersection of the thick solid line which stands for the average carbon content in austenite upon cooling with the extrapolation of the $\mathrm{w}_{\mathrm{C}}^{\gamma / \alpha}$ line.

The dilatometry experiments mentioned above showed also that carbon transfer from austenite to graphite during cooling was much slower than calculated on a basis of diffusion control, when the opposite, i.e. dissolution of graphite in austenite during heating, matched very well diffusion control calculations. That carbon transfer to graphite is slower than calculated for diffusion control is in fact in accordance with results by Birchenall and $\mathrm{Mead}^{15)}$ on graphitization of white cast irons where carbon transfer was found to be 5-10 times slower than expected. Such a difference could be due to stress effect as investigated by Hillert ${ }^{16)}$ in the case of graphitization of steels or by an interfacial reaction for carbon transfer from austenite to graphite. Simple calculations by Silva et al. ${ }^{1718)}$ showed an increased compression towards the graphite/austenite interface that is compatible with a decreased diffusion rate of carbon, though a more precise approach would be necessary to conclude quantitatively on the relative role of stress and interface kinetics.

\subsection{Formation of Pearlite}

Johnson and Kovacs ${ }^{1)}$ and later Venugopalan ${ }^{3)}$ considered pearlite grows in cast irons as it does in steels and this is also accepted here. Numerous studies on low-carbon Fe-C$\mathrm{X}$ alloys have been reported describing growth of pearlite during isothermal holding after austenitization and quenching to a temperature where pearlite could nucleate and grow. Owing to silicon being the predominant alloying element, it is of first interest to look at the detailed description of the different growth conditions for pearlite in $\mathrm{Fe}-\mathrm{C}-\mathrm{Si}$ alloys described by Hillert. ${ }^{20)}$ At high temperatures, i.e. at temperatures located within the three phase field of the metastable system, meta-pearlite could grow that involves long range redistribution of substitutional alloying elements

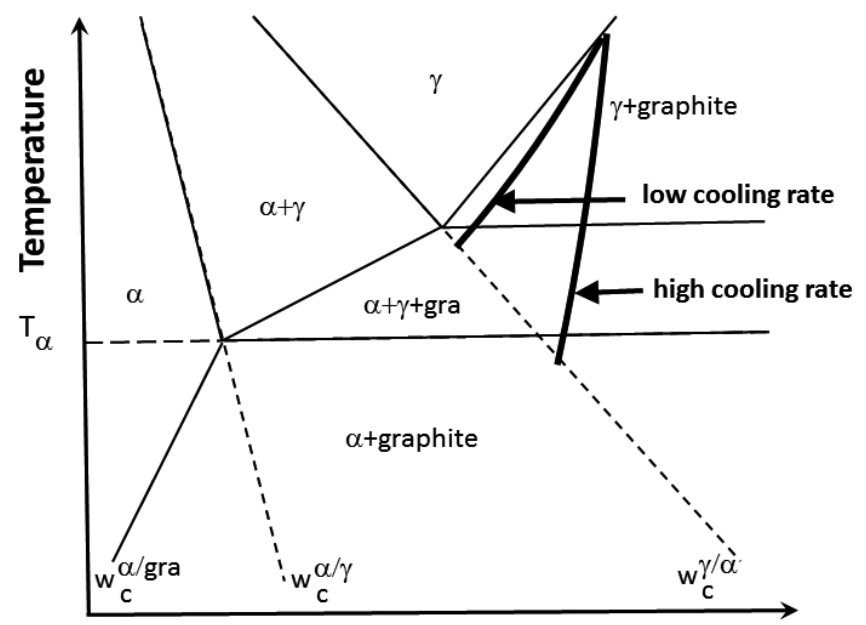

Carbon content

Fig. 6. Isopleth $\mathrm{Fe}-\mathrm{C}$ section of the phase diagram showing the possible evolution of the average carbon content in austenite (very thick lines) during cooling at low and high cooling rate. in austenite. At lower temperature, but still above the lower limit of the three-phase field, divergent ortho-pearlite may be observed when the carbon activity in austenite is very high. The two above cases could not apply to cast irons because of the presence of graphite precipitates that act as carbon sink and limit any increase of carbon activity in austenite. For temperature below the lower limit of the three-phase field, constant ortho-pearlite and para-pearlite grow at low and high undercooling respectively. In both of these two latter growth processes, Hillert ${ }^{20)}$ demonstrated that pearlite inherits the composition of the parent austenite, so that its growth kinetics is controlled by carbon diffusion in austenite. It is however worth to mention the role of carbon diffusion in ferrite that Nakajima et $a .^{21)}$ have been pointed out by phase field modelling of binary $\mathrm{Fe}-\mathrm{C}$ alloys. Unfortunately, no such work is yet available for ternary or multicomponent alloys.

According to Hillert, ${ }^{20)}$ constant ortho-pearlite grows with full partitioning of substitutional solutes between cementite and ferrite while para-pearlite grows with no such partitioning, i.e. both cementite and ferrite inherit the austenite composition. In case of constant ortho-pearlite as in cast irons, partitioning of substitutional alloying elements is expected to control lamellar spacing within pearlite. The temperature for the transition between constant ortho-pearlite and parapearlite in $\mathrm{Fe}-\mathrm{C}-\mathrm{Si}$ alloys decreases strongly with the silicon content. It is so low at $2-3 \mathrm{wt} . \% \mathrm{Si}$ that only constant ortho-pearlite needs being considered in the case of cast irons. To check if the assumed similarity between constant ortho-pearlite in steels and in cast irons is valid, Lacaze ${ }^{22)}$ analyzed literature data for the start of the pearlitic reaction during isothermal treatment of various cast irons and compared with the results of Al-Salman et al. ${ }^{23)}$ on a $\mathrm{Fe}-\mathrm{C}-\mathrm{Si}$ steel. A strong agreement was found in that results for the steel and for cast irons with 2.2 to $3.4 \mathrm{wt} . \% \mathrm{Si}$ all fall on a common pearlite nose with little scattering.

The fact that pearlite forming during continuous cooling of cast irons inherits the composition of the parent austenite allows describing the pearlitic reaction in a $\mathrm{Fe}-\mathrm{C}$ isopleth section of the metastable system as done before for the ferritic reaction in the stable system. Such an isopleth section is illustrated in Fig. 7. As for the ferritic reaction, Lacaze et $a{ }^{5,6)}$ suggested that the pearlitic reaction takes place only when the temperature of the alloy has reached the lower limit of the three-phase field. The reference temperature for pearlite formation should thus be given by the intersection of the extrapolated austenite/ferrite boundary with the lower limit of the three phase field. This temperature is denoted $T_{p}$ in Fig. 7. Using again the Thermocalc software ${ }^{9)}$ and data from Uhrenius, ${ }^{10)}$ the following equation was proposed for $\mathrm{T}_{\mathrm{p}}\left({ }^{\circ} \mathrm{C}\right)$ by Gerval and Lacaze: $:^{8)}$

$$
\begin{aligned}
\mathrm{T}_{\mathrm{p}} & =727+21.6 \cdot \mathrm{w}_{\mathrm{Si}}+0.023 \cdot\left(\mathrm{w}_{\mathrm{Si}}\right)^{2}-21.0 \cdot \mathrm{w}_{\mathrm{Cu}} \\
& -25.0 \cdot \mathrm{w}_{\mathrm{Mn}}+8.0 \cdot \mathrm{w}_{\mathrm{Mo}}+13.0 \cdot \mathrm{w}_{\mathrm{Cr}}-33.0 \cdot \mathrm{w}_{\mathrm{Ni}}
\end{aligned}
$$

For all elements, the composition domain of use of this equation is the same as indicated for $\mathrm{T}_{\alpha}$. It is interesting to note that ferrite stabilizers as silicon and molybdenum do increase $T_{p}$, while the strong negative effect of copper, manganese and nickel is to be related to them being austenite stabilizers. For what concerns chromium, the increase in $T_{p}$ 


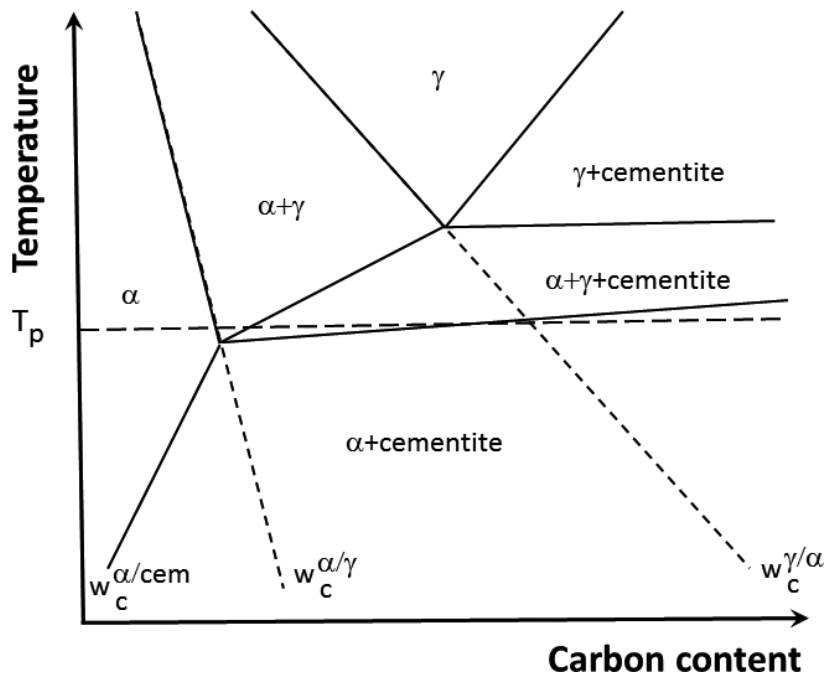

Fig. 7. Isopleth $\mathrm{Fe}-\mathrm{C}$ section of the $\mathrm{Fe}-\mathrm{C}-\mathrm{Si}$ system at $2.5 \mathrm{wt} . \%$ $\mathrm{Si}$ in the metastable eutectoid range.

should be due to the fact it is a carbide former owing to the above remark on the downward gamma loop in this system.

As done previously for the start of the ferritic reaction, results for the detected start of the pearlitic reaction may conveniently be represented as undercooling $\Delta \mathrm{T}_{\mathrm{p}}$ calculated with respect to $T_{p}$ expressed as: $\Delta T_{p}=T_{p}-T$, where $T$ is the observed onset temperature of the transformation. Figure 5 shows there is a minimum undercooling necessary for pearlite to nucleate at finite cooling rate, which amounts to about $40^{\circ} \mathrm{C}$ for alloys containing copper and manganese according to the results by Sertucha et al. ${ }^{4)}$ Because results on the ferritic reaction have shown easy nucleation of ferrite, it can be claimed that such an undercooling for the pearlitic reaction relates to difficulties in nucleation of cementite.

Owing to the growth mechanism of pearlite, the undercooling for its formation increases much less when the cooling rate increases as compared to the ferritic reaction. Accordingly, the curves for the start of the ferritic and pearlitic reactions intersect for a cooling rate of about $180^{\circ} \mathrm{C} \cdot \mathrm{min}^{-1}$ for the alloys illustrated in Fig. 5, and no ferrite would form above this critical cooling rate. As for the ferritic reaction, it is quite possible that the reported undercoolings are overestimated because the transformation will be detected by the thermocouples only after a significant volume fraction of pearlite has appeared. Comparison between thermal analysis or DTA experiments and dilatometry results could certainly confirm this claim but the authors are not aware of such a work.

Based on works on multi-component steels, Venugopalan ${ }^{3)}$ described pearlite growth in nodular cast irons with a model fitted on TTT diagrams. In this work, the equation describing pearlite growth was the same for all cast irons except those containing molybdenum. This agrees with detailed experimental studies by Lalich and Loper ${ }^{19)}$ and Pan et al. ${ }^{2)}$ which have been analyzed in terms of growth kinetics by Lacaze. $^{22)}$ Alloys with up to 0.75 wt.\% Mn, 2 wt.\% Cu, 0.5 wt. $\%$ As and 0.3 wt. $\%$ Sn all showed similar pearlite growth rates. Lacaze and Sertucha ${ }^{24)}$ confirmed this applies as well for alloys with copper up to $0.9 \mathrm{wt} . \%$ and tin up to $0.11 \mathrm{wt} . \%$. It may thus be concluded that pearlite growth in cast iron is controlled by silicon partitioning between fer- rite and cementite even when (low) additions of the above elements have been made to the cast iron. Based on a fit of experimental data by Al Salman et al. ${ }^{23)}$ for a silicon steel, the growth rate of pearlite could then be expressed as function of $\Delta \mathrm{T}_{\mathrm{p}}$ as

$$
\mathrm{V}_{\mathrm{p}}=7 \cdot 10^{-5} \cdot\left(\Delta \mathrm{T}_{\mathrm{p}}\right)^{3} \exp \left[-20 \times \Delta \mathrm{T}_{\mathrm{p}} /(\mathrm{T}+273)\right] \mu \mathrm{m} \cdot \mathrm{s}^{-1} \ldots
$$

which allows reproducing the pearlite nose.

As stressed above, Eq. (4) would not work for cast irons containing molybdenum and certainly also chromium which are known to affect the growth rate of pearlite in cast irons as seen, for example, in the extensive compilation of TTT and CCT curves by Röhrig and Fairhurst. ${ }^{25)}$ The decrease in pearlite growth kinetics observed when these elements are added is in agreement with the fact that they are known to strongly affect carbon diffusion in austenite which has been stated to control constant ortho-pearlite growth.

Finally, alloying with elements that do not dissolve in cementite and have little solubility in ferrite, such as copper, could have been expected to affect pearlite growth rate as they should strongly partition. It does not appear this partitioning has any effect in the case of copper, and this would certainly be worth of further investigation.

\section{Growth Competition of Ferritic and Pearlitic Reac- tions}

From above, it would appear that there is a temperature window in which ferrite could grow without the risk of pearlite appearing for usual cast irons. For a homogeneous matrix, this window could be expressed as $\Delta \mathrm{T}=\mathrm{T}_{\alpha}-\mathrm{T}_{\mathrm{p}}$ :

$$
\begin{aligned}
\Delta \mathrm{T} & =12-3.2 \cdot \mathrm{w}_{\mathrm{Si}}+1.977 \cdot\left(\mathrm{w}_{\mathrm{Si}}\right)^{2}+7 \cdot \mathrm{w}_{\mathrm{Cu}} \\
& -20 \cdot \mathrm{w}_{\mathrm{Mn}}-6 \cdot \mathrm{w}_{\mathrm{Mo}}-37 \cdot \mathrm{w}_{\mathrm{Cr}}+6.5 \cdot \mathrm{w}_{\mathrm{Ni}}
\end{aligned}
$$

From Eq. (5) it would be concluded that manganese is a strong pearlite promoter, while chromium and molybdenum are very strong and mid pearlite promoter respectively. Copper and nickel appear as mid ferrite promoters while they are generally reported to be pearlite promoters. It may thus be concluded that considering the temperature difference for the start of ferritic and pearlitic reactions could be valid for isothermal transformations, but is not sufficient for analyzing the effect of these usual alloying elements on as-cast materials which are continuously cooled during the eutectoid transformation.

\subsection{Effects of Pearlite Promoters}

The way copper and manganese act on the eutectoid transformation has led to several, potentially contradictory, explanations as reviewed by Pan et al. ${ }^{2)}$ In a later work on the effects of alloying on the eutectoid transformation in cast irons, Venugopalan ${ }^{3)}$ summarized the role of austenite promoters such as copper, manganese and nickel by stating they all decrease the temperature for the ferritic reaction, but have different effect on carbon diffusion: manganese would decrease it, nickel would leave it unchanged while copper would form a barrier around the nodules that retards carbon transfer to graphite as suggested by Lalich and Loper. ${ }^{19)}$ As seen above, these three elements do effectively depress the stable eutectoid temperature which then certainly leads to 
a decrease in the diffusion coefficient of carbon in ferrite. However, this may not be sufficient to explain their pearlite promoting effect because it is not expected that additions of substitutional elements at the level used for copper, manganese and nickel (excluding austenitic cast irons) in cast irons would dramatically affect carbon diffusion coefficient in ferrite.

Figure 8 shows the effect of 1 wt. $\% \mathrm{Cu}, 1$ wt.\% $\mathrm{Mn}$ and 1 wt. $\% \mathrm{Ni}$ on the ferrite/austenite boundary in an isopleth $\mathrm{Fe}-\mathrm{C}$ section at $2.5 \mathrm{wt} . \% \mathrm{Si}$ calculated with Thermocalc ${ }^{9)}$ and the TC-FE4 databank. All the lines in the section are shown for the ternary $\mathrm{Fe}-\mathrm{C}-\mathrm{Si}$ alloy while only the ferrite/ austenite boundary with its extrapolation below the ferrite/ graphite line (dashed line) is shown for the three $\mathrm{Fe}-\mathrm{C}$ $2.5 \mathrm{Si}-\mathrm{X}$ alloys. Note that the temperature of the intersection between these two boundaries is the $\mathrm{T}_{\alpha}$ temperature because the lower limit of the stable three phase field is nearly horizontal in every case (see Fig. 4). Addition of 0.25 wt.\% chromium or molybdenum was found to change very little the $\mathrm{T}_{\alpha}$ temperature, and it is worth stressing also that all of the above additions did leave the ferrite/graphite boundary unchanged.

It is seen in Fig. 8 that, at given temperature, any addition of copper, nickel and manganese would lead to a decrease of the driving force for carbon diffusion from austenite to graphite, expressed here as $\Delta \mathrm{w}_{\mathrm{C}}$, and thus would decrease the amount of ferrite. At given undercooling $\Delta \mathrm{T}_{\alpha}$, the driving force is seen to be left unchanged by addition of copper, nickel, and the same is valid for chromium or molybdenum. On the contrary, manganese is seen to decrease the carbon content in ferrite at the ferrite/austenite equilibrium, thus decreasing $\Delta \mathrm{w}_{\mathrm{C}}$, hence its very well-known pearlite promoting effect.

However, all the above elements but molybdenum do decrease $\mathrm{T}_{\alpha}$, and thus lead to a decrease of the carbon diffusion coefficients during the ferritic reaction (Table 1). It is seen that in addition to the usual temperature effect, the diffusion coefficient in ferrite drops significantly at the ferrite Curie temperature. The Curie temperature of pure iron is $770^{\circ} \mathrm{C}$ and decreases with addition of $\mathrm{Cr}, \mathrm{Cu}, \mathrm{Mn}, \mathrm{Mo}, \mathrm{Ni}$ and Si. Sertucha et al. ${ }^{4)}$ found experimentally it to be $744^{\circ} \mathrm{C}$

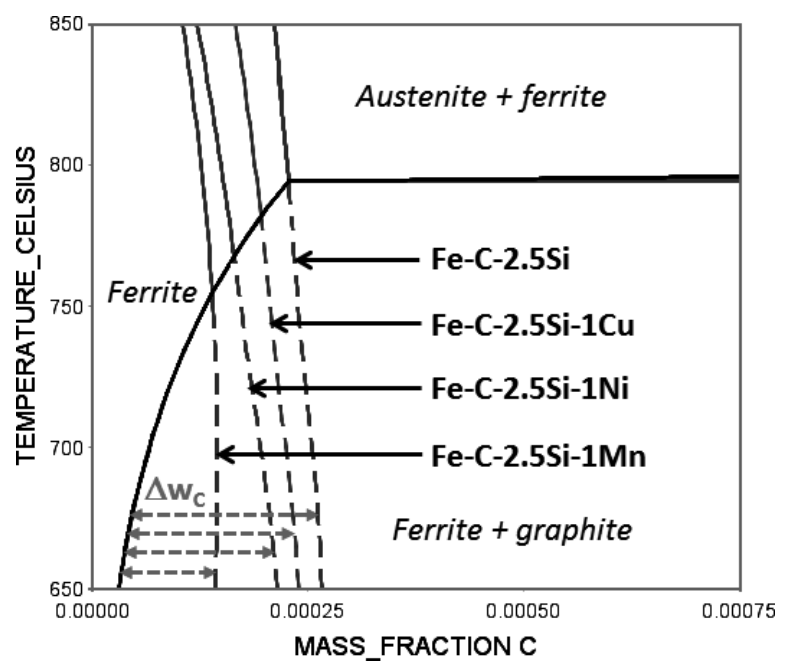

Fig. 8. Effect of $1 \mathrm{wt} . \% \mathrm{Cu}, \mathrm{Mn}$ or $\mathrm{Ni}$ on $\Delta \mathrm{w}_{\mathrm{C}}$ for an alloy with 2.5 wt.\% Si. for a cast iron with 3.79 wt. \% C, 0.02 wt.\% Cr, 0.11 wt.\% $\mathrm{Cu}, 0.19$ wt.\% $\mathrm{Mn}$ and 2.51 wt.\% Si.

From Fig. 8 it would be expected that low addition of copper would not affect the ferritic reaction, and Lalich and Loper ${ }^{19)}$ have effectively reported that small addition (0.2-0.3 wt.\%) of copper does not affect it. Lacaze et al. ${ }^{5)}$ noticed that copper favors slightly the ferritic reaction when added at similar low level. The known pearlite promoting effect of copper appears at higher content as illustrated in Fig. 9. It is seen that there exists a critical amount of copper, about 0.6 wt. $\%$, at which the ferrite fraction drops suddenly at given cooling conditions. Sertucha et al. ${ }^{4)}$ then suggested that when the alloy composition is such that the ferritic reaction proceeds at temperature below the Curie temperature, it is abruptly slowed down because of the drop in the carbon diffusion coefficient in ferrite.

Figure 9 illustrates also the sensitivity of the final microstructure to cooling rate, which results from the competition of growth in the stable and metastable systems. Furthermore, Askeland and Gupta ${ }^{26)}$ have shown that the relative amount of ferrite and pearlite is sensitive to change in nodule counts or cooling rate only when the nodule count is low. When the nodule count is high, extremely rapid cooling rates are required to suppress ferrite growth.

The analysis of literature data performed by Lacaze et

Table 1. Diffusion coefficients $\left(\mathrm{m}^{2} \cdot \mathrm{s}^{-1}\right)$ of carbon in austenite, $\mathrm{D}_{\mathrm{C}}^{\gamma}$, and in ferrite, $\mathrm{D}_{\mathrm{C}}^{\alpha}$. $\mathrm{T}_{\text {Curie }}$ is the Curie temperature of ferrite.

$\mathrm{D}_{\mathrm{C}}^{\gamma}=2.343 \cdot 10^{-5} \cdot \exp \left(-\frac{17767}{\mathrm{~T}+273}\right) \quad\left(\right.$ Liu and Agren $\left.^{49)}\right)$
$\mathrm{D}_{\mathrm{C}}^{\alpha}=2 \cdot 10^{-6} \cdot \exp \left(-\frac{10115}{\mathrm{~T}+273}\right)$
$\cdot \exp \left\{0.5898 \cdot\left[1+\frac{2}{\pi} \cdot \arctan \left(\frac{15629}{\mathrm{~T}_{\text {Curie }}+273}-\frac{15309}{\mathrm{~T}+273}\right)\right]\right\} \quad\left(\right.$ Agren $\left.^{50)}\right)$

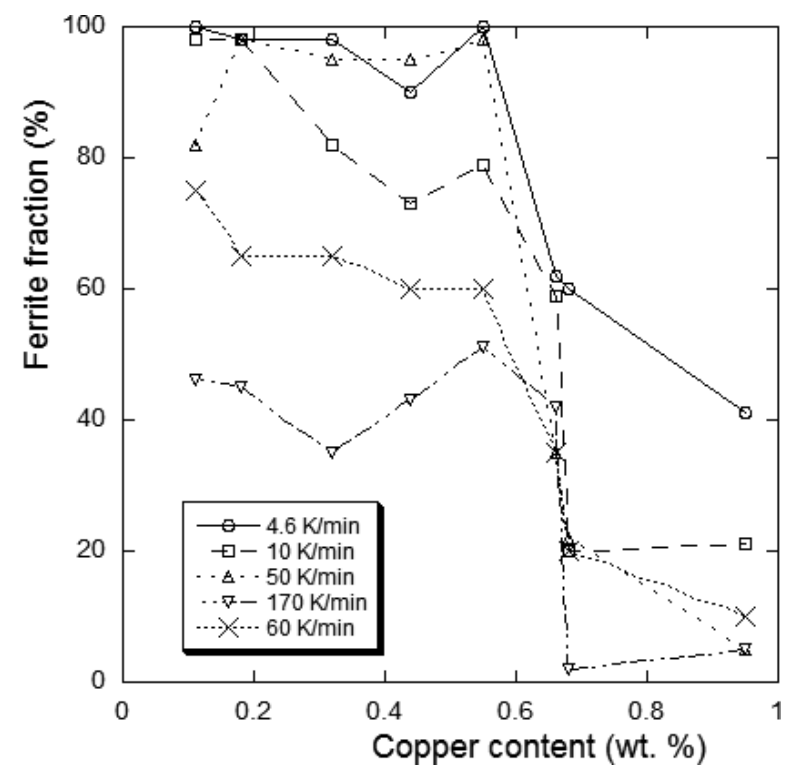

Fig. 9. Effect of copper addition on the ferrite fraction after cooling at different rates after austenitization or casting in a thermal analysis cup $\left(60^{\circ} \mathrm{C} / \mathrm{min}\right)$. The alloys contained 3.6-3.8 wt.\% C, 2.5-2.8 wt.\% Si, 0.12-0.19 wt.\% Mn. After Sertucha et al. ${ }^{4)}$ 
$a l .{ }^{27)}$ showed that the same kind of behavior as seen for copper in Fig. 9 exists for tin with a critical amount at about 0.05 wt.\%. Available results concerning manganese present a more regular effect though it could not be excluded that a drop exists also for this element. Considering data obtained by Pan et $a l^{2)}$ on thermal analysis cups, a tin equivalent $\left(\mathrm{Sn}_{\mathrm{eq}}\right)$ could be defined as:

$$
\mathrm{Sn}_{\mathrm{eq}}=0.075 \cdot \mathrm{w}_{\mathrm{Mn}}+0.125 \cdot \mathrm{w}_{\mathrm{Cu}}+\mathrm{w}_{\mathrm{Sn}}
$$

For the thermal conditions prevailing in thermal analysis cups, it was found that a fully pearlitic matrix could be obtained for $\mathrm{Sn}_{\text {eq }}$ equal to or higher than $0.13 \mathrm{wt} . \%$. However, as already stated by Guerin and Gagné, ${ }^{28)}$ it could also be concluded from literature data that addition of copper and manganese alone, i.e. without tin, would hardly lead to a fully pearlitic matrix.

Johnson and Kovacs ${ }^{1)}$ and Kovacs ${ }^{29)}$ compared the role of manganese, tin and antimony, as pearlite promoters. Using Auger analysis, they reported tin and antimony to form a thin layer at the surface of graphite that would be a barrier to the transfer of carbon to nodules. However, Kovacs ${ }^{29)}$ mentions that such a diffusion barrier could not be evidenced at the matrix-flake interface in grey iron, while tin and antimony are pearlite promoters for these alloys as well. Thus, as considered by Johnson and Kovacs, ${ }^{1)}$ this layer may have formed in the solid state by rejection of tin and antimony from graphite. This further suggests that there should be a strong interaction between carbon atoms on the basal planes of graphite and tin or antimony that limits carbon transfer from the matrix to graphite and thus leads to their pearlite promoter effect.

A comparison of the $\mathrm{Fe}-\mathrm{Si}$ and $\mathrm{Fe}-\mathrm{Sn}$ diagrams which present a similar gamma loop indicates that tin is a ferrite stabilizer. Accordingly, tin is expected to increase both the $\mathrm{T}_{\alpha}$ and $\mathrm{T}_{\mathrm{p}}$ temperatures, a fact reported by Pan et al. ${ }^{2)}$ on an experimental basis. Looking at the slope of the gamma loop, Lacaze and Sertucha ${ }^{24)}$ proposed that a term $+21 \cdot \mathrm{w}_{\mathrm{Sn}}$ could be added to Eq. (3). Accounting for this term, it was found that $\Delta \mathrm{T}_{\mathrm{p}}$ extrapolates to zero at zero cooling rate for cast irons alloyed with more than 0.05 wt.\% Sn. This suggests that Sn acts in strongly decreasing the undercooling for cementite precipitation and thus for pearlite formation. The $\mathrm{Fe}-\mathrm{Sb}$ phase diagram presents a gamma loop very similar to that of the Fe-Sn system, which suggests its effect on pearlite growth may have the same reason. There is however a clear need for detailed information on the $\mathrm{Fe}-\mathrm{C}-\mathrm{Sb}$ and $\mathrm{Fe}-\mathrm{C}-\mathrm{Sn}$ systems to validate this conclusion.

Cho et $a l .{ }^{30)}$ have reported that small additions (up to 0.3 wt.\%) of Mo and Ni promote ferrite, while higher levels of these elements alone or in combination promote pearlite, as observed by Hsu et al. ${ }^{31)}$ for $\mathrm{Co}$ and $\mathrm{Ni}$, Nobuki et $a{ }^{32)}$ for $\mathrm{Ni}$ and Mn, Lacaze et al. ${ }^{33)}$ for $\mathrm{Ni}$ and $\mathrm{Yu}$ and Loper ${ }^{34)}$ for $\mathrm{Mo}, \mathrm{Cu}$ and Ni. Venugopalan and Alagarsamy ${ }^{35)}$ related the pearlite promoter effect of nickel to its effect on the eutectoid temperature. These authors discussed also the complex effect of molybdenum in the same line as those followed by $\mathrm{Yu}$ and Loper, ${ }^{34)}$ considering molybdenum decreases carbon diffusion in ferrite. Gruzin and Mural $^{36}$ ) have effectively reported long ago such an effect of molybdenum. That molybdenum decreases carbon diffusion in ferrite and in austenite, as already pointed out, would explain that addition of this element to cast irons does shift the ferritic and pearlitic reactions to longer times in TTT and CCT diagrams as could be seen in the compendium of Rohrig and Fairhurst. ${ }^{25)}$

\subsection{Impurities and Trace Elements Effects}

Björkegren $^{37)}$ has reviewed some of the relations available at the beginning of the 1980's to relate composition and ferrite or pearlite fraction for given casting conditions. The still most extensive work available is the one published by Thielemann ${ }^{38)}$ who proposed the following relation for the fraction of ferrite in the matrix $(\%)$ :

$$
\mathrm{f}_{\text {ferrite }}=961 \cdot \exp (-\mathrm{Px})
$$

where Px is a linear relation of the contents in manganese, silicon, copper, tin, lead, bismuth, arsenic, chromium and antimony. Equation (7) is meaningful provided Px is higher than 2.3 for the fraction of ferrite to be lower than $100 \%$.

The exponential relation in Eq. (7) agrees with the abrupt drop of the ferrite fraction seen in Fig. 9, which means in turn that the work by Thielemann was certainly focused on pearlitic grades. Though it is worth stressing that a study by Motz and Rörhig ${ }^{39)}$ reported quantitative information on the effect of sulfur and lead, the work by Thielemann is the only one which considered quantitatively both alloying and trace elements. Magnusson-Åberg et al. ${ }^{40)}$ suggested to use manganese and tin equivalents reported in the literature to complement the expression of Px for accounting for other elements and arrived at the following relation:

$$
\begin{aligned}
& \mathrm{PX}=3.00 \cdot\left[\mathrm{w}_{\mathrm{Mn}}+1.5 \cdot \mathrm{w}_{\mathrm{Ni}}+5.2 \cdot \mathrm{w}_{\mathrm{Ti}}+1.2 \cdot \mathrm{w}_{\mathrm{V}}+1.7 \cdot \mathrm{w}_{\mathrm{Mo}}\right] \\
& -2.65 \cdot\left(\mathrm{w}_{\mathrm{Si}}-2.0\right)+7.75 \cdot \mathrm{w}_{\mathrm{Cu}}+90.0 \cdot\left[\mathrm{w}_{\mathrm{Sn}}-0.185 \cdot \mathrm{w}_{\mathrm{Co}}\right. \\
& \left.+0.138 \cdot \mathrm{w}_{\mathrm{Mg}}+0.75 \cdot \mathrm{w}_{\mathrm{N}}+0.067 \cdot \mathrm{w}_{\mathrm{P}}\right]+357 \cdot \mathrm{w}_{\mathrm{Pb}}+333 \cdot \mathrm{w}_{\mathrm{Bi}} \\
& +20.1 \cdot \mathrm{w}_{\mathrm{As}}+9.60 \cdot \mathrm{w}_{\mathrm{Cr}}+71.7 \cdot \mathrm{w}_{\mathrm{Sb}}
\end{aligned}
$$

Magnusson-Åberg et al. ${ }^{40)}$ applied Eq. (8) to data from other authors than Thielemann and found a satisfactory description of the transition from ferritic-pearlitic to fully pearlitic matrix. In particular, it could be noticed that accounting for minor elements such as magnesium or for impurities such as phosphorus was important: in any series of data from a given source, accounting for these elements decreased the scattering. However, the scattering of the data from various sources remained high which may be due because cooling rate differed from one study to another.

Another source of scattering is the nodule count which may greatly vary even when melt preparation and casting parameters are expected to be constant. Such a variability has been observed by Sertucha et al. ${ }^{41)}$ who reported that the nodule count $\left(\mathrm{N}_{\mathrm{A}}\right)$ varied from $190 \mathrm{~mm}^{-2}$ to $590 \mathrm{~mm}^{-2}$ at given casting and inoculation conditions. The composition ranges of the four series of alloys that were investigated are given in Table 2 for the main elements and Table $\mathbf{3}$ for the low level elements. Interestingly enough, it could be observed a two-fold relation between $\mathrm{N}_{\mathrm{A}}$ and sulfur as seen in Fig. 10. Half of the data showed no sensitivity to the sulfur content while the other half showed a clear increase of $\mathrm{N}_{\mathrm{A}}$ with the content in sulfur. As seen in this figure, this was observed for both fully ferritic and partly pearlitic casts. Looking systematically at the change in composition of the various alloys investigated during this study, it could be 
Table 2. Composition ranges in main elements (wt.\%), and extreme values of nodule number $\mathrm{N}_{\mathrm{A}}\left(\mathrm{mm}^{-2}\right) \mathrm{and} \mathrm{ferrite}^{-}$ fraction $\mathrm{f}^{\alpha}(\%)$ for the four series.

\begin{tabular}{|c|c|c|c|c|c|c|c|c|c|c|}
\hline Series & $\mathrm{C}$ & $\mathrm{Si}$ & $\mathrm{Mn}$ & $\mathrm{P}$ & $\mathrm{S}$ & $\mathrm{Ni}$ & $\mathrm{Cu}$ & $\mathrm{Mg}$ & $\mathrm{N}_{\mathrm{A}}$ & $\mathrm{f}^{\alpha}$ \\
\hline \multirow{2}{*}{ ferritic series } & 3.36 & 1.51 & 0.09 & 0.017 & 0.004 & 0 & 0.01 & 0.021 & 190 & 75 \\
\hline & 4.08 & 4.16 & 0.39 & 0.042 & 0.02 & 0.27 & 0.15 & 0.059 & 590 & 100 \\
\hline \multirow{2}{*}{ Ni series } & 3.75 & 1.40 & 0.09 & 0.012 & 0.003 & 0.04 & 0.01 & 0.052 & 147 & 24 \\
\hline & 3.94 & 1.88 & 0.13 & 0.014 & 0.005 & 0.94 & 0.02 & 0.058 & 191 & 44 \\
\hline \multirow{2}{*}{ Si series } & 3.02 & 2.20 & 0.05 & 0.016 & 0.005 & 0.030 & $<0.020$ & 0.033 & 136 & 89 \\
\hline & 3.84 & 3.81 & 0.11 & 0.032 & 0.009 & 0.073 & 0.052 & 0.060 & 323 & 100 \\
\hline \multirow{2}{*}{ Pearlitic series } & 2.32 & 1.66 & 0.12 & 0.012 & 0.008 & 0.026 & 0.0045 & 0.44 & 95 & 0 \\
\hline & 4.08 & 2.97 & 1.06 & 0.045 & 0.021 & 0.060 & 1.18 & 1.72 & 460 & 30 \\
\hline
\end{tabular}

Table 3. Composition ranges in other elements (wt.\%) of the four series.

\begin{tabular}{|c|c|c|c|c|c|c|c|c|c|c|c|c|}
\hline Series & B & $\mathrm{Ti}$ & $\mathrm{Al}$ & $\mathrm{Bi}$ & $\mathrm{N}$ & $\mathrm{Nb}$ & $\mathrm{Zr}$ & $\mathrm{Cr}$ & $\mathrm{Sn}$ & Mo & $\mathrm{V}$ & $\mathrm{Sb}$ \\
\hline \multirow{2}{*}{ ferritic series } & 0 & 0 & 0 & 0 & 0.0032 & 0 & 0 & & & & & \\
\hline & 0.032 & 0.028 & 0.017 & 0.005 & 0.0077 & 0.012 & 0.003 & & & & & \\
\hline \multirow{2}{*}{ Ni series } & & $<0.01$ & & & & & & 0.02 & $<0.005$ & $<0.01$ & & \\
\hline & & & & & & & & 0.05 & & 0.01 & & \\
\hline \multirow{2}{*}{ Si series } & & & 0.006 & & & & & 0.029 & & $<0.01$ & & \\
\hline & & & 0.014 & & & & & 0.045 & & 0.013 & & \\
\hline \multirow{2}{*}{ Pearlitic series } & 0 & 0 & 0 & & 0 & 0 & 0 & 0 & 0 & 0 & 0 & 0 \\
\hline & 0.0067 & 0.36 & 0.02 & & 0.0086 & 0.46 & 0.005 & 0.35 & 0.025 & 0.98 & 0.5 & 0.005 \\
\hline
\end{tabular}

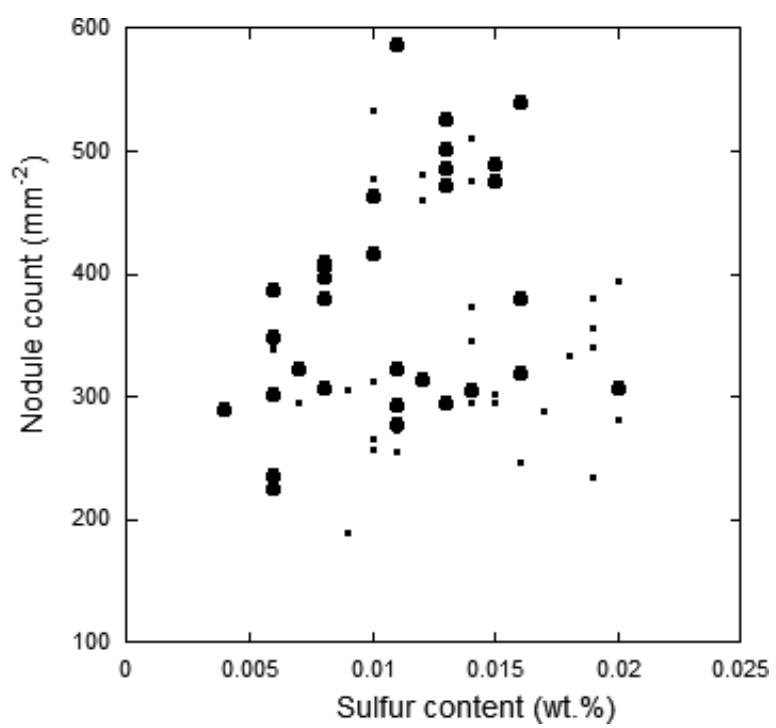

Fig. 10. Evolution of the nodule count $\mathrm{N}_{\mathrm{A}}$ with the sulfur content of fully ferritic (large circles) and partly pearlitic (small circles) as-cast alloys, after Sertucha et al. ${ }^{41)}$

noticed that copper and titanium contents presented also a two-fold correlation with the sulfur content. This suggests that very complex chemical reactions take place during melt preparation that would preclude any possibility of predicting matrix microstructure to a significant degree of accuracy without an appropriate description of these reactions which is far from being available.

\subsection{Microsegregation}

As stressed for example by Dorazil, ${ }^{42)}$ microsegregation issued from the solidification step can greatly affect solidstate transformations. However, Gerval and Lacaze ${ }^{43)}$ used experimental characterization of the microsegregations to calculate the local $\mathrm{T}_{\alpha}$ and $\mathrm{T}_{\mathrm{p}}$ temperatures and found these temperatures do not change much for $80 \%$ of the matrix. Further these results illustrated clearly that the undercooling of the ferritic reaction increases all along the transformation, while it increases at the beginning and then remains constant for the pearlitic reaction. This is in line with the above description of these reactions.

Because solidification is controlled by carbon diffusion, build-up of microsegregation of other solutes depends on it as calculated by Lacaze. ${ }^{44)}$ However, a calculation based on Scheil's model for substitutional solutes but assuming rapid solid-state diffusion of carbon may conveniently represent the development of microsegregation during solidification of nodular cast iron. Such a calculation was performed using the Scheil's module of Thermocalc ${ }^{9)}$ with the TC-Fe4 database selecting an alloy in the middle range of those studied by Rundman, ${ }^{45)}$ namely with $2.25 \% \mathrm{Si}, 0.5 \% \mathrm{Mn}, 0.5 \% \mathrm{Cu}$, $1 \% \mathrm{Ni}$ and $0.1 \% \mathrm{Mo}$ (in wt.\%). The carbon content was set at $3.6 \mathrm{wt} . \%$ to give a eutectic composition and $0.1 \mathrm{wt} \% \mathrm{Cr}$ was also added. In Fig. 11, the composition of austenite is plotted versus solid fraction which is "equivalent" to the distance from the surface of a nodule (solid fraction equal to zero) to half distance between two neighboring nodules (solid fraction equal to one). Note the logarithmic scale of the $\mathrm{Y}$ axis in Fig. 11. It is seen that the predicted microsegre- 


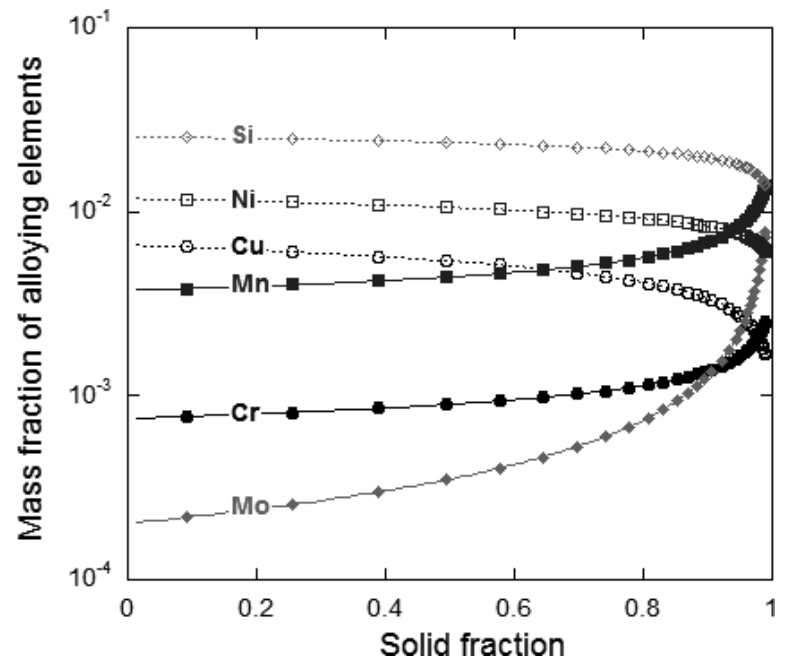

Fig. 11. Build-up of microsegregation of some substitutional solutes in the austenite matrix during solidification of a eutectic nodular graphite cast iron, note the logarithmic scale for plotting austenite composition. The origin of the $\mathrm{X}$ axis corresponds to the outer surface of nodules, i.e. the start of the eutectic reaction.

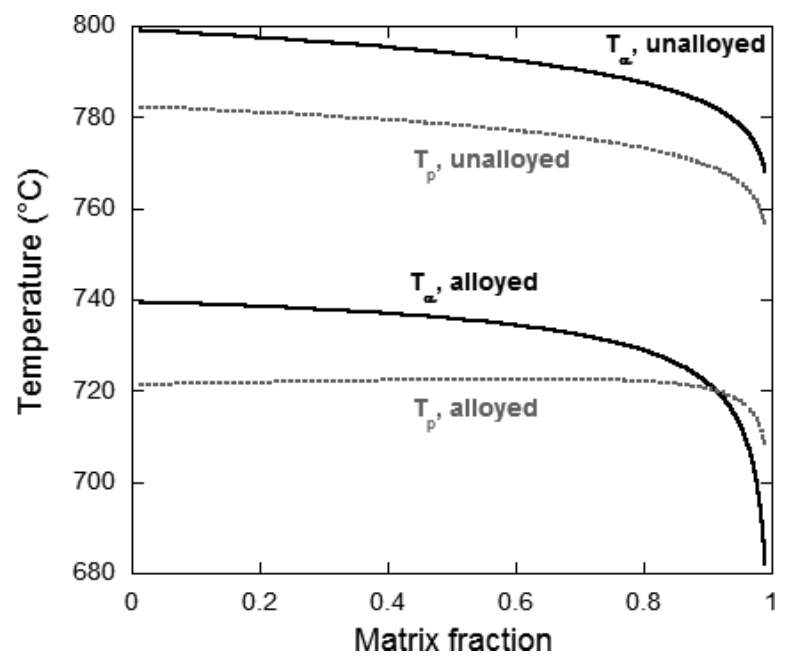

Fig. 12. Local reference temperatures for the ferritic and pearlitic reactions calculated along the composition profiles in Fig. 11. Both the case of an unalloyed cast iron and of an alloyed one are shown.

gations agree very well with those measured by Rundman ${ }^{45)}$ and with information from literature he reported.

Figure 12 illustrates the local evolutions of $T_{\alpha}$ and $T_{p}$ for the above alloy and compares them to those for the unalloyed cast iron (Fe-3.6 wt.\% C-2.5 wt.\% Si). Note that the correction given by Eq. (2) was not applied here. As expected the first effect of alloying is to shift the temperatures for the start of the stable and metastable transformations to much lower temperatures, eventually below the Curie temperature of ferrite. The second effect is to affect the temperature difference between these two reactions which are seen to intersect at some point away from the graphite nodules in alloyed iron when they remain well separated in the unalloyed one. This is seen to be due to the fact that $T_{p}$ remains constant and even increases because of the marked segregation of molybdenum and chromium which affect positively $T_{p}$. Both of these effects will favor the formation of pearlite instead of ferrite.

While austenite was considered as chemically homogeneous in the previous sections, the graph in Fig. 11 shows this is not the case and the graph in Fig. 12 demonstrates how this affects the local reference temperatures. Accordingly, it may be expected that the reference temperature for pearlite formation will depend on the fact the final matrix is fully pearlitic or not. In ferrito-pearlitic matrix, the pearlitic reaction has been observed to start at higher undercooling than in fully pearlitic matrix as reported by Samuel and Viswanathan ${ }^{46)}$ and Lacaze and Sertucha. ${ }^{24)}$ This is certainly to be associated with microsegregation.

\section{Conclusion}

Control of the eutectoid transformation of austenite to get a fully ferritic or fully pearlitic matrix is achieved by alloying or by change in the cooling rate (which depends in all practicality on the casting section size). The most common pearlite promoter alloying elements are manganese, copper and tin, but elements present as impurities or traces may greatly affect the final microstructure. Increase of the nodule count may also have a positive effect on ferrite fraction by favoring carbon diffusion from austenite to graphite nodules and by multiplying the possible sites for ferrite nucleation, but it has been stated this is more effective at low nodule count. More precisely, the matrix structure of low nodule count nodular cast irons will be sensitive to cooling rate while very high cooling rates would be necessary to avoid some ferrite forming at high nodule count.

Impurities or trace elements appear to have a marked effect on graphite shape and on room temperature properties. However, the many possible interactions between them make difficult to properly define rules for controlling cast iron melt chemistry. Attempts made in the past such as the extensive work by Thielemann ${ }^{38)}$ should be updated as impurities and their level are not the same in the present days as they were at that time. Supporting such a work with the development of an appropriate databank for thermodynamic calculations of inclusion formation during melt preparation and solidification is certainly worth of an attempt. Finally, dedicated studies of growth kinetics of pearlite when elements such as nickel, molybdenum and chromium are present would be of great interest.

\section{REFERENCES}

1) W. C. Johnson and B. V. Kovacs: Metall. Trans. A, 9 (1978), 219.

2) E. N. Pan, M. S. Lou and C. R. Loper: AFS Trans., 95 (1987), 819.

3) D. Venugopalan: Proc. Int. Symp. Fundamentals and Applications of Ternary Diffusion, ed. by G. R. Purdy, Pergamon Press, New York, (1990), 173.

4) J. Sertucha, P. Larrañaga, J. Lacaze and M. Insausti: Int. J. Metalcast., winter issue (2010), 51.

5) J. Lacaze, S. Ford, C. Wilson and E. Dubu: Scand. J. Metall., 22 (1993), 300.

6) J. Lacaze, C. Wilson and C. Bak: Scand. J. Metall., 23 (1994), 151.

7) J. Lacaze, A. Boudot, V. Gerval, D. Oquab and H. Santos: Metall Mater. Trans. A, 28 (1997), 2015.

8) V. Gerval and J. Lacaze: ISIJ Int., 40 (2000), 386.

9) J. O. Andersson, T. Helander, L. Höglund, P. F. Shi and B. Sundman: Calphad, 26 (2002), 273.

10) B. Uhrenius: Proc. Symp. Hardenability Concepts with Application to Steel, ed. by D. V. Doane and J. S. Kirkaldy, Metallurgical Society of AIME, Warrendale, (1977), 28.

11) J. E. Rehder: AFS Trans., 73 (1965), 473.

12) B. F. Brown and M. F. Hawkes: AFS Trans., 59 (1951), 181 
13) F. Hellal, J. Lacaze and A. Hazotte: Mater. Sci. Technol., 15 (1999), 773.

14) A. Hazotte, H. Santos and J. Lacaze: Int. J. Cast Met. Res., 16 (2003), 155.

15) C. E. Birchenall and H. W. Mead: Trans. AIME, 206 (1951), 1004.

16) M. Hillert: Jernkontorets Ann., 141 (1967), 67.

17) R. J. C. Silva, F. M. Braz Fernandes, A. Hazotte, F. Hellal, J. Lacaze, S. Denis and A. M. Pinto: Mater. Sci. Forum, 404-407 (2002), 165.

18) R. J. C. Silva, A. Hazotte, H. C. M. Santos, A. M. Pinto, J. Lacaze, F. M. Braz Fernandes and F. Hellal: Int. J. Cast Met. Res., 16 (2003), 149.

19) M. J. Lalich and C. R. Loper: AFS Trans., 81 (1973), 217.

20) M. Hillert: Proc. Int. Conf. Solid/solid Phase Transformations, ed. by H. I. Aaronson, D. E. Laughlin, R. F. Sekerka and C. M. Wayman, Metallurgical Society of AIME, Warrendale, (1982), 789.

21) K. Nakajima, M. Apel and I. Steinbach: Acta Mater., 54 (2006), 3665.

22) J. Lacaze: Inter. J. Cast Met. Res., 11 (1999), 431.

23) S. A. Al-Salman, G. W. Lorimer and N. Ridley: Acta Metall., 27 (1979), 1391.

24) J. Lacaze and J. Sertucha: Int. J. Cast Met. Res., 29 (2016), 74, doi: $10.1080 / 13640461.2016 .1142238$.

25) K. Röhrig and W. Fairhurst: Heat Treatment of Nodular Cast Iron, Transformation Diagrams. VDG Taschenbücher, Giesserei-Verlag GmbH, Düsseldorf, (1979).

26) D. R. Askeland and S. S. Gupta: AFS Trans., 83 (1975), 313.

27) J. Lacaze, J. Sertucha, P. Larrañaga and R. Suárez: Archives Metall. Mater., in press.

28) L. Guerin and M. Gagné: The Foudryman, 80 (1987), 336.

29) B. V. Kovacs: AFS Trans., 89 (1981), 79.

30) G. S. Cho, K. H. Choe, K. W. Lee and A. Ikenaga: Mater. Sci. Technol., 23 (2007), 97.

31) G. H. Hsu, M. L. Chen and C. J. Hu: Mater. Sci. Eng. A., 444 (2007), 339.

32) T. Nobuki, M. Hatate and T. Shiota: Int. J. Cast Met. Res., 21 (2008), 31.

33) J. Lacaze, P. Larranaga, I. Asenjo, R. Suárez and J. Sertucha: Mater. Sci. Technol., 28 (2012), 603.

34) S. K. Yu and C. R. Loper: AFS Trans., 96 (1988), 811.

35) D. Venugopalan and A. Alagarsamy: AFS Trans., 98 (1990), 395.

36) P. L. Gruzin and V. V. Mural: Translated from Metalovedenie I Termicheskaya Obrabotka Metallov, 3 (1969), 70

37) L. E. Björkegren: Föroreningsämnen i gjutjärn. Gjuterinytt $n^{\circ} 445$, Svenska Gjuteriföreningen, Jönköping, (1981).

38) T. Thielemann: Giessereitechnik, 16 (1970), 16

39) J. Motz and K. Rörhig: Giessereiforschung, 22 (1970), 109 (in English).

40) L. Magnusson Åberg, C. Hartung and J. Lacaze: Proc. Int. Symp. Science and Processing of Cast Iron, SPCI-10, Mar del Plata, Argentina, 2014, Repositorio Institucional INTEMA-Facultad de Ingeniería, Universidad Nacional de Mar del Plata, http://rinfi.fi.mdp.edu.ar/ xmlui/handle/123456789/28 (accessed 2016-03-01).

41) J. Sertucha, J. Lacaze, J. Serrallach, R. Suárez and F. Osuna: Mater Sci. Technol., 28 (2012), 184.

42) E. Dorazil: High Strength Austempered Cast Iron. Ellis Horwood, London, (1991), 13.

43) V. Gerval and J. Lacaze: Proc. Int. Conf. Solidification 97, eds. by J.
Beech and H. Jones, The University of Sheffield, Sheffield, (1997), 506 (in English).

44) J. Lacaze: Acta Mater., 47 (1999), 3779.

45) K. B. Rundman: Annual AFS Congress Proceedings, Paper 117, (1997).

46) C. Samuel and S. Viswanathan: AFS Trans., 117 (2009), 563.

47) J. Fridberg, L.-E. Törndahl and M. Hillert: Jernkontorets Ann., 131 (1969), 263

48) X. Guo and D. M. Stefanescu: Int. J. Cast Met. Res., 11 (1999), 437.

49) Z. K. Liu and J. Ågren: Acta Metall., 37 (1989), 3157.

50) J. Ågren: Scr. Metall., 20 (1986), 1507.

\section{Appendix}

Redistribution of substitutional elements between ferrite and austenite or between pearlite and austenite during austenite decomposition needs long range diffusion of these elements in austenite in front of the growing interface. The thickness of the corresponding diffusion spike would scale as $\mathrm{D} / \mathrm{V}$ where $\mathrm{D}$ is the diffusion coefficient in austenite and $\mathrm{V}$ the growth rate of the interface.

Diffusion coefficients in iron, either ferrite or austenite, have been compiled by Fridberg et al. $^{47)}$ who reported all diffusion coefficients of substitutional solutes are within 0.5 to 5 times the self-diffusion coefficient of iron in austenite, 0.8 to 3 times in the case of ferrite. The selfdiffusion coefficient of iron in austenite was given as $7 \cdot 10^{-5} \cdot \exp (-34400 / \mathrm{T}) \mathrm{m}^{2} \cdot \mathrm{s}^{-1}$, where $\mathrm{T}$ is expressed in Kelvin. For a transformation proceeding at $700^{\circ} \mathrm{C}$ as in Fig. 2 , the diffusion coefficient takes a value of $3 \cdot 10^{-20} \mathrm{~m}^{2} \cdot \mathrm{s}^{-1}$. It is seen in Fig. 2 that the duration of the transformation is typically $200 \mathrm{~s}$. With an half-distance between nodules of 10-50 $\mu \mathrm{m}$, the typical thickness of the diffusion spike in front of the interface would thus be $6 \cdot 10^{-13}$ to $1.2 \cdot 10^{-13} \mathrm{~m}$. This unphysical distance definitely confirms that there is no redistribution of substitutional solutes.

The same should apply to the pearlitic reaction which proceeds at even larger growth rates than the ferritic reaction. Thus, long range redistribution reported by Guo and Stefanescu ${ }^{48)}$ seems questionable and suggests there were strong chemical heterogeneities in their alloys due to the precipitation of eutectic carbides that were then totally or partly dissolved during austenitization. 